\title{
A Descriptive Model for the Kinetics of Gas Release in Different Types of Pizzas
}

\author{
M.L. CABO, L. PASTORIZA, AND J.J. RODRÍGUEZ
}

\begin{abstract}
A model based on typical equations of microbial kinetics is proposed to describe gas release (GR) in ham, tuna, and meat pizzas packaged under different $\mathrm{CO}_{2}$-enriched atmospheres: $20 \% \mathrm{CO}_{2}, 70 \% \mathrm{CO}_{2}$, and $70 \% \mathrm{CO}_{2}$ plus $500 \mathrm{mg} / \mathrm{kg}$ Nisaplin. $\mathrm{CO}_{2}$-enriched atmospheres hardly influenced LAB growth but reduced GR, which points to the importance of yeasts for GR. Nonetheless, LAB also contributed significantly to GR, so Nisaplin also delayed GR. Gas release followed a diauxic pattern, the 2nd stage being presumably related to yeasts shifting from respiratory to fermentative metabolism once oxygen was depleted. However, storing pizzas for longer than 25 to $30 \mathrm{~d}$ does not seem appropriate in terms of shelf life, so the model proposed appears adequate for practical purposes.
\end{abstract}

Keywords: pizza, Nisaplin, $\mathrm{CO}_{2}$, modeling, antibacterial activity

\section{Introduction}

$S_{\text {to }}^{\mathrm{w}}$ WELLING OF PACKS DUE TO GAS RELEASE IS A MAJOR PROBLEM IN MANY foods. Heterofermentative lactic acid bacteria, yeasts, and lactose positive coliforms have been identified as responsible for $\mathrm{CO}_{2}$ production in most cases (salads: Birzele and others 1997; cooked meat products: Sameshima and others 1997; Samelis and others 2000; cheese: Westall and Filtenborg 1998; fish products: Lyhs and others 2001).

This was also the case in modified atmosphere packaged precooked ham pizzas, but the combination of packaging under a $\mathrm{CO}_{2}-$ enriched atmosphere and adding Nisaplin $\left(10^{6} \mathrm{IU}\right.$ nisin per g, Applin \& Barrett Ltd., Dorset, U.K.) prevented swelling and increased shelf life significantly (Cabo and others 2001). This combination was found to act synergistically presumably because of a complementary effect, since $\mathrm{CO}_{2}$ inhibits the growth of yeasts and nisin inhibits LAB.

These results were of a great interest for the food industry, so it was considered that it would be useful to find out if they were confirmed in other kinds of pizzas of the same line of production. It would allow that only one mathematical model could be used to describe the effects of nisin and $\mathrm{CO}_{2}$ on the kinetics of gas release. This could be very helpful for the food industry as a first step to shelf-life prediction and control of critical points of the production line.

Foods usually spoil as a result of microbial activity, which causes severe changes in chemical and sensory properties. Modeling is often used to describe the effects of state variables (Devlieghere and others 1998; Koutsoumanis and others 2000; Erkmen 2000; Castillejo Rodríguez and others 2000) on the kinetics of microbial growth. Considering the complex microbial ecology of food systems, monitoring some of those changes would be clearly advantageous in highly heterogeneous foods, such as pizzas, where several different microorganisms contribute to spoilage.

This work has therefore aimed the development of a model to describe the kinetics of gas release in various kinds of pizzas packaged under different gas mixtures in the presence and absence of Nisaplin.

\section{Materials and Methods}

\section{Experimental design}

Each experimental unit consisted of one single pizza (about 400 g) made up of $265 \mathrm{~g}$ of dough (pre-cooked at $300^{\circ} \mathrm{C}$ for $2 \mathrm{~min}$ ), $65 \mathrm{~g}$ of tomato paste, cheese substitute, and a number of different ingredients (ham pizza: ham, mushrooms, and olives; tuna pizza: tuna, onions, and olives; meat pizza: meat and bacon; cheese pizza: Emmental, mozzarella and cheddar cheeses; pepperoni pizza: pepperoni).

The independent variables of the study were the content of Nisaplin (500 mg/kg or absence) and the initial proportion of $\mathrm{CO}_{2}$ in the gas mixture ( 20 or $70 \%$ ). These values were selected in accordance with a previous study (Cabo and others 2001).

Nisaplin ( $10^{6} \mathrm{IU}$ nisin per g) solutions were prepared in sterile distilled water immediately prior to addition, and added by spraying on top of the pizza and by mixing with the tomato paste. A same volume of water, that is no Nisaplin, was added to a number of pizzas which were used as controls. The content of Nisaplin per pizza always refers to the total added amount.

Once all the ingredients had been added, pizzas were placed into a thermo-moulded laminate, and subsequently the gas mixture (Carburos Metálicos S.A., Galicia, Spain) was injected and immediately another laminate was sealed on top by using a vacuumcompensated heat sealer (TF-1000, ULMA, Galicia, Spain). Gas mixtures contained $\mathrm{N}_{2}$ as filler, and the system of packaging enabled some residual oxygen $(\sim 1 \%)$ to be left in the headspace with the aim of preventing the growth of anaerobic pathogens (Church and Parsons 1995).

Packed-pizzas were stored at $7 \pm 1{ }^{\circ} \mathrm{C}$. This temperature was chosen to simulate real conditions during distribution and storage at retail outlets. Triplicate samples of each treatment were subjected to a number of analyses at different periods of storage. Unless specified, sampling was interrupted whenever pizzas were rejected by sensory panels.

\section{Microbiological and chemical measurements}

Pizzas were randomly cut into small pieces ( 3 to $4 \mathrm{~g}$ ). A homogeneous mixture was obtained by transferring several of these pieces (about $25 \mathrm{~g}$ ) into a sterile plastic Stomacher bag and blending with sterile peptone water (Panreac S.A., Spain) in the ratio 1:9 (w/v) by means of a Seward Stomacher lab-blender (Model 400, Seward Medical, London, U.K.). Subsequently, homogenates were serial diluted in peptone water, and $0.1 \mathrm{~mL}$ aliquots were spread on Petri 
plates by triplicate. LAB counts were carried out on MRS agar (Panreac S.A.) after incubation at $37^{\circ} \mathrm{C}$ for $2 \mathrm{~d}$. Yeasts were enumerated on Malt Extract Agar (Panreac S.A) by incubation at $25^{\circ} \mathrm{C}$ during 5 d.

The proportions of $\mathrm{CO}_{2}$ and $\mathrm{O}_{2}$ in the headspace were determined by using a PAK 12P headspace analyser (Abiss S.A.R.L., France). The amount of gas released (GR) is defined as the increase (at each sampling time) in the proportion of $\mathrm{CO}_{2}$ in the headspace respect to that injected. In a preliminary experiment swelling was determined only semi-quantitatively by using two gauges (22 and $28 \mathrm{~mm}$ high), so packs were classified in 3 different categories: lower than $22 \mathrm{~mm}$, between 22 and $28 \mathrm{~mm}$, and higher than $28 \mathrm{~mm}$.

\section{Mathematical modeling}

Bearing in mind that the inhibition of microbial growth by any factor normally results in a decrease of the asymptote or the specific growth rate, the kinetics of growth of LAB (L) were defined by using a classic logistic equation:

$$
\mathrm{L}=\frac{\mathrm{k}^{\prime}}{1+\mathrm{c}^{\prime} \times \mathrm{e}^{-\mu^{\prime} \times \mathrm{t}}}
$$

where the parameters $\mu^{\prime}$ and $k^{\prime}$ were defined as a function of the concentration of Nisaplin and the initial proportion of $\mathrm{CO}_{2}$ in the gas mixture as follows:

$$
\begin{aligned}
& \mathrm{k}^{\prime}=\frac{\mathrm{k}}{1+\mathrm{a}_{\mathrm{k}^{\prime}} \times[\mathrm{N}]+\mathrm{b}_{\mathrm{k}^{\prime}} \times[\mathrm{C}]} \\
& \mu^{\prime}=\frac{\mu}{1+\mathrm{a}_{\mu^{\prime}} \times[\mathrm{N}]+\mathrm{b}_{\mu^{\prime}} \times[\mathrm{C}]}
\end{aligned}
$$

$k$ : maximum biomass of $\mathrm{LAB}$ in the absence of Nisaplin and $\mathrm{CO}_{2}$, expressed as log CFU per $g$ of sample; $\mu$ : specific growth rate of $\mathrm{LAB}$ in the absence of Nisaplin and $\mathrm{CO}_{2}$ (biomass formed per unit of present biomass and per unit of time, dimensions time ${ }^{-1}$ ); $k^{\prime}$ : maximum biomass of LAB in the presence of Nisaplin or $\mathrm{CO}_{2}$; $\mu^{\prime}$ : specific growth rate of $\mathrm{LAB}$ in the presence of Nisaplin or $\mathrm{CO}_{2}$.

$$
\mathrm{c}^{\prime}=\frac{\mathrm{k}}{L_{0}}-1
$$

where $\mathrm{L}_{0}$ is the initial biomass of $\mathrm{LAB} ; N$ : concentration of Nisaplin, expressed as $\mathrm{mg} / \mathrm{kg}$ of pizza; $C$ : initial proportion (\%) of $\mathrm{CO}_{2}$ in the gas mixture; $a_{k^{\prime}}$ and $b_{k^{\prime}}$ : empirical parameters defining the degree of influence of Nisaplin and $\mathrm{CO}_{2}$, respectively, on the maximum biomass of LAB; and $a_{\mu^{\prime}}$ and $b_{\mu}$ : empirical parameters defining the degree of influence of Nisaplin and $\mathrm{CO}_{2}$, respectively, on the specific growth rate.

Considering the microbial origin of the gas released (Cabo and others 2001), GR was also defined by a similar logistic-type equation:

$$
\mathrm{GR}=\frac{\mathrm{A}^{\prime}}{1+\mathrm{Z}^{\prime} \times \mathrm{e}^{-\mathrm{r}^{\prime}} \times \mathrm{t}}
$$

in which the parameters $\mathrm{A}^{\prime}$ and $\mathrm{r}^{\prime}$ were also defined as a function of the concentration of Nisaplin and the initial proportion of $\mathrm{CO}_{2}$ in the gas mixture as follows:

$$
\mathrm{A}^{\prime}=\frac{\mathrm{A}}{1+\mathrm{a}_{\mathrm{A}^{\prime}} \times[\mathrm{N}]+\mathrm{b}_{\mathrm{A}^{\prime}} \times[\mathrm{C}]}
$$

$$
\mathrm{r}^{\prime}=\frac{\mathrm{r}}{1+\mathrm{a}_{\mathrm{r}^{\prime}}^{\prime} \times[\mathrm{N}]+\mathrm{b}_{\mathrm{r}^{\prime}} \times[\mathrm{C}]}
$$

$A^{\prime}$ : maximum amount of gas released in the presence of Nisaplin or $\mathrm{CO}_{2} ; r^{\prime}$ : specific gas release (dimensions $\mathrm{T}-1$ ) in the presence of Nisaplin or $\mathrm{CO}_{2}$; $A$ : maximum amount of gas released in the absence of Nisaplin and $\mathrm{CO}_{2}$, expressed as percentage respect to the total amount of $\mathrm{CO}_{2}$ present; and $r$ : specific gas release in the absence of Nisaplin and $\mathrm{CO}_{2}$ (dimensions $\mathrm{T}-1$ ).

$$
\mathrm{z}^{\prime}=\frac{\mathrm{A}^{\prime}}{G R_{0}}-1
$$

where $G R_{0}$ is the amount of gas released at zero time; $a_{A^{\prime}}$ and $b_{A^{\prime}}$ : empirical parameters defining the degree of influence of Nisaplin and $\mathrm{CO}_{2}$, respectively, on the maximum amount of gas released; $a_{r^{\prime}}$ and $b_{r}$ : empirical parameters defining the degree of influence of Nisaplin and $\mathrm{CO}_{2}$, respectively, on the specific gas release; and $G R_{0}$ is conceptually zero, but Eq. 4 fails to make such an estimate and provides values higher than zero for the origin ordinate. Consequently, this estimate must be substracted from Eq. 4 (Cabo and others 1999) as follows:

$$
\mathrm{GR}=\mathrm{A}^{\prime} \frac{1}{1+\mathrm{z}^{\prime} \times \mathrm{e}^{-\mathrm{r}^{\prime} \times t}}-\left(\frac{1}{\mathrm{z}^{\prime}+1}\right)
$$

To substract the origin ordinate provides an estimate for $A^{\prime}$ that does not correspond to the actual value for the asymptote. The latter, however, can be determined by calculation of the limit when time becomes infinite (Murado and others 2002):

$$
A^{\prime} \max =\lim _{t \rightarrow \infty} A^{\prime}=A^{\prime} \times\left(\frac{z^{\prime}}{z^{\prime}+1}\right)
$$

Fits of Eq. 1 and 5 to experimental data were performed according to a least-squares method (quasi-Newton). All calculations were carried out by using a Microsoft Excel program.

\section{Results and Discussion}

I N A PRELIMINARY EXPERIMENT, MEASUREMENTS OF SWELLING AFTER 21 $\mathrm{d}$ of storage in 100 samples of each ham, tuna, and meat pizzas packed under 20 or $70 \% \mathrm{CO}_{2}$ in the presence of Nisaplin $(500 \mathrm{mg} /$ $\mathrm{kg}$ ) showed similar response patterns (Figure 1). That is, most $20 \%$ $\mathrm{CO}_{2}$ packed-pizzas had swollen above $22 \mathrm{~mm}$ and many even above $28 \mathrm{~mm}$, while swelling had hardly occurred in pizzas packaged under $70 \% \mathrm{CO}_{2}$ in the presence of Nisaplin. In contrast, patterns were dissimilar for cheese or pepperoni pizzas since swelling was lower for both types of treatments.

Accordingly, this work was focused on the development of a model describing the combined effects of Nisaplin and packaging under $\mathrm{CO}_{2}$-enriched atmospheres on the kinetics of gas release in ham, tuna, and meat pizzas, the shelf-lives of which were significantly shorter according to previous studies (results not shown). With this aim, a comparative study was made for each of these pizzas among 3 different treatments: packaging under $20 \% \mathrm{CO}_{2}$ (that is, commercial treatment), packaging under $70 \% \mathrm{CO}_{2}$, and packaging under $70 \% \mathrm{CO}_{2}$ plus addition of $500 \mathrm{mg}$ Nisaplin per $\mathrm{kg}$ of pizza.

Though a high number of $\mathrm{LAB}\left(>10^{7} \mathrm{CFU} / \mathrm{ml}\right)$ is rapidly reached in modified atmosphere packaged-pizzas, it has a reduced signif- 
Table 1-Values for the parameters of the Eq. 1 of LAB growth in ham, tuna, and meat pizzas packaged under $20 \%$ $\mathrm{CO}_{2}$ (A), $70 \% \mathrm{CO}_{2}$ (B), and $70 \% \mathrm{CO}_{2}$ plus $500 \mathrm{mg} / \mathrm{kg}$ of Nisaplin (C)

\begin{tabular}{|c|c|c|c|c|c|c|c|c|c|}
\hline & \multicolumn{3}{|c|}{ Ham pizza } & \multicolumn{3}{|c|}{ Tuna pizza } & \multicolumn{3}{|c|}{ Meat pizza } \\
\hline & $\mathbf{A}$ & B & C & A & B & C & $\mathbf{A}$ & B & C \\
\hline $\mathrm{k}^{\prime}$ & 9.34 & 8.87 & 8.56 & 9.00 & 8.76 & 8.58 & 9.05 & 8.60 & 8.18 \\
\hline$\mu^{\prime}$ & 0.190 & 0.232 & 0.147 & 0.911 & 0.989 & 0.187 & 0.775 & 0.911 & 0.221 \\
\hline$r^{2}$ & & 0.994 & & & 0.994 & & & 0.967 & \\
\hline $\mathrm{n}^{*}$ & & 22 & & & 14 & & & 14 & \\
\hline
\end{tabular}

${ }^{*}$ number of experimental data

icance in terms of food safety and is not immediate responsible for the development of off-flavors and off-odors (Cabo and others 2001). In fact, the loss of quality results from the activity of very many different $\mathrm{LAB}$ and yeasts, which cause acidification and the release of $\mathrm{CO}_{2}$ (Cabo and others 2001) so swelling becomes the major limiting factor for the shelf life of MAP-pizzas.

The growth of LAB and GR were successfully described by Eq. 1 and 5, respectively. High values for the correlation coefficients be- tween experimental data (either of LAB counts or amount of gas released) and estimates from each equation were achieved for all pizzas (Table 1 and 2). Additionally, residual plots did not show any suspicious regularity in any case either (Figure 2 and 3). Both sets of results proved the goodness of fit of the 2 models.

Comparing the values for the parameters of these models is useful to assess how much Nisaplin and $\mathrm{CO}_{2}$ reduced the spoilage of those pizzas. For instance, the growth rates $\left(\mu^{\prime}\right)$ of LAB decreased
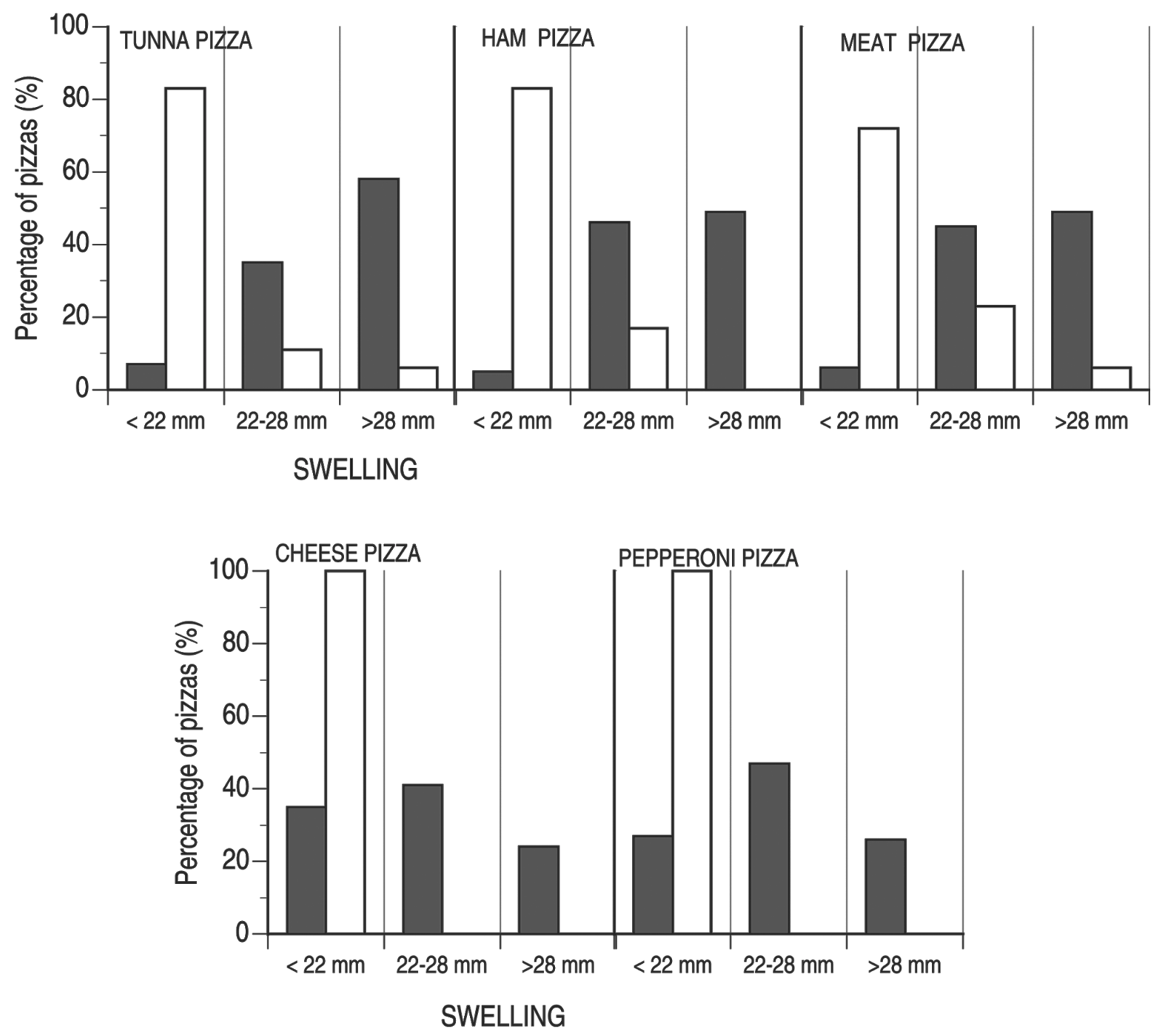

Figure 1-Swelling of ham, tuna, meat, cheese and pepperoni pizzas packaged under $20 \% \mathrm{CO}_{2}$ (filled bars) or $70 \%$ $\mathrm{CO}_{2}$ in the presence of $500 \mathrm{mg} / \mathrm{kg}$ of Nisaplin (unfilled bars) after $21 \mathrm{~d}$ of storage. 
Table 2-Values for the parameters of the Eq. 5 of gas release in ham, tuna, and meat pizzas packaged under $20 \%$ $\mathrm{CO}_{2}$ (A), $70 \% \mathrm{CO}_{2}$ (B), and $70 \% \mathrm{CO}_{2}$ plus $500 \mathrm{mg} / \mathrm{kg}$ of Nisaplin (C)

\begin{tabular}{|c|c|c|c|c|c|c|c|c|c|}
\hline & \multicolumn{3}{|c|}{ Ham pizza } & \multicolumn{3}{|c|}{ Tuna pizza } & \multicolumn{3}{|c|}{ Meat pizza } \\
\hline & A & B & C & A & B & C & A & B & C \\
\hline $\begin{array}{l}\mathrm{A}^{\prime} \\
\mathrm{r}^{\prime} \\
\mathrm{z}^{\prime}\end{array}$ & $\begin{array}{c}46.42 \\
0.450 \\
37.13\end{array}$ & $\begin{array}{c}28.55 \\
0.194 \\
22.45\end{array}$ & $\begin{array}{c}20.46 \\
0.120 \\
15.81\end{array}$ & $\begin{array}{c}42.53 \\
0.822 \\
325.0\end{array}$ & $\begin{array}{c}20.37 \\
0.690 \\
155.15\end{array}$ & $\begin{array}{c}16.99 \\
0.291 \\
129.24\end{array}$ & $\begin{array}{c}44.24 \\
0.683 \\
138.06\end{array}$ & $\begin{array}{c}20.56 \\
0.550 \\
63.62\end{array}$ & $\begin{array}{c}20.31 \\
0.220 \\
62.84\end{array}$ \\
\hline $\begin{array}{l}r^{2} \\
n^{*}\end{array}$ & \multicolumn{3}{|c|}{$\begin{array}{l}0.983 \\
29\end{array}$} & \multicolumn{3}{|c|}{$\begin{array}{l}0.996 \\
20\end{array}$} & \multicolumn{3}{|c|}{$\begin{array}{l}0.991 \\
21\end{array}$} \\
\hline
\end{tabular}

*number of experimental data

significantly as a result of the addition of Nisaplin (Table 1), and this is presumably related to the decreases in the rates of gas release $\left(r^{\prime}\right)$ when Nisaplin was added (Table 2).

The most relevant finding, however, results from the fact that significant decreases in $A^{\prime}$ and $r^{\prime}$ when pizzas were packed under $70 \% \mathrm{CO}_{2}$ (compared with $20 \% \mathrm{CO}_{2}$ ) did not correspond with similar decreases in $k^{\prime}$ and $\mu^{\prime}$. That is, GR did not follow the kinetics of LAB growth (Figures 4 and 5). In fact, although a retarding effect of $\mathrm{CO}_{2}$ on the growth of LAB has been noted in a few cases (Ahvenainen

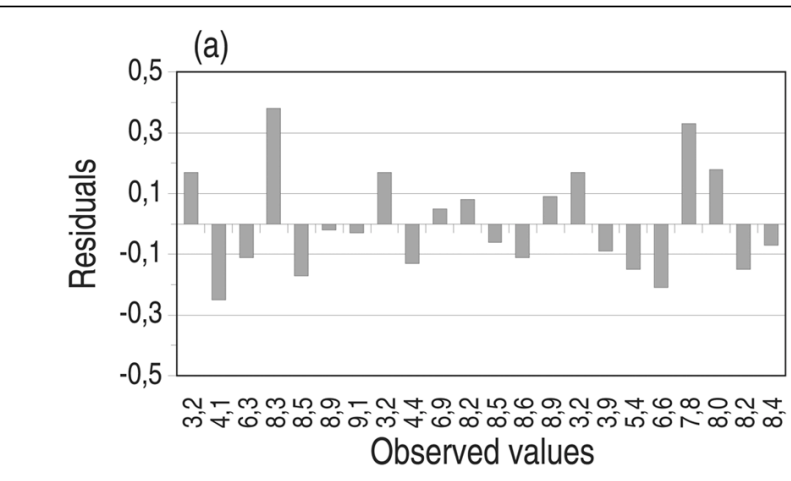

(b)

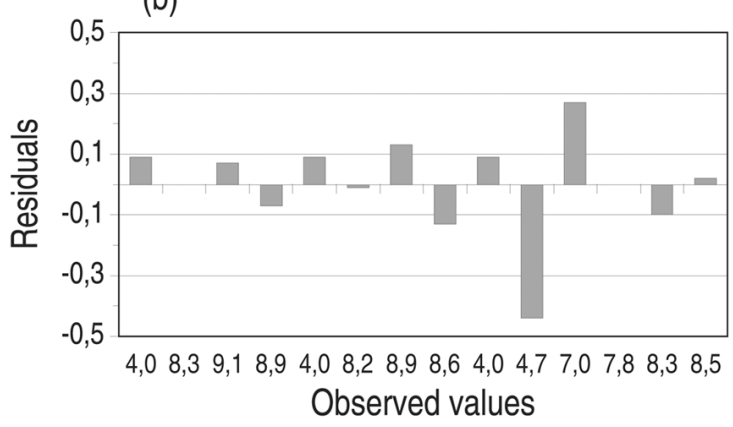

(c)

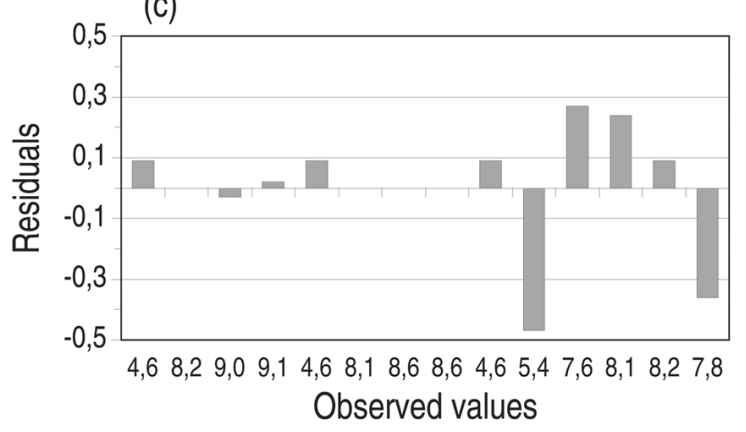

Figure 2-Residual plots for the Eq. 1 of LAB growth in ham (a), tuna (b), and meat (c) pizzas and others 1990; Borch and others 1996), the present case followed the general trend (Lannelongue and others 1982; Layrisse and Matches 1984), and so the value of $\mu^{\prime}$ was even slightly higher for pizzas stored under $70 \% \mathrm{CO}_{2}$ than for those subjected to commercial treatment. On the contrary, yeast counts were lower in pizzas stored under $70 \% \mathrm{CO}_{2}$ than in those under commercial treatment (Table 3 ). The inhibition of yeasts by high $\mathrm{CO}_{2}$ concentrations is well-

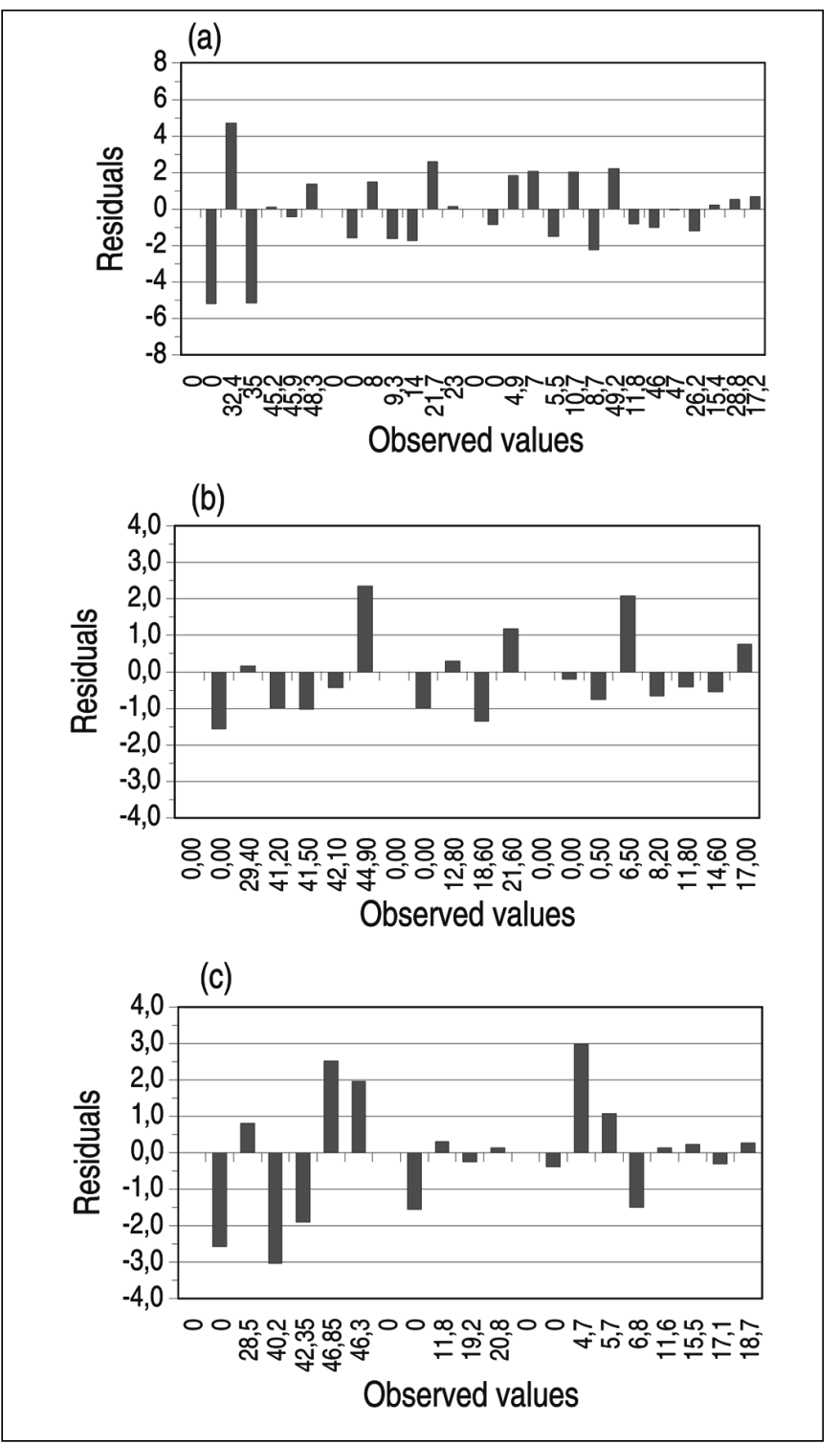

Figure 3-Residual plots for the Eq. 5 of the amount of gas released (GR) in ham (a), tuna (b), and meat (c) pizzas 
Table 3-Yeast counts (log CFU/g) in ham, tuna, and meat pizzas packaged under $20 \% \mathrm{CO}_{2}(\mathrm{~A}), 70 \% \mathrm{CO}_{2}(\mathrm{~B})$, and $70 \%$ $\mathrm{CO}_{2}$ plus $500 \mathrm{mg} / \mathrm{kg}$ of Nisaplin (C)

\begin{tabular}{|c|c|c|c|c|c|c|c|c|c|}
\hline \multirow[b]{2}{*}{ Days } & \multicolumn{3}{|c|}{ Ham pizza } & \multicolumn{3}{|c|}{ Tuna pizza } & \multicolumn{3}{|c|}{ Meat pizza } \\
\hline & A & B & C & A & B & C & A & B & C \\
\hline 3 & 2.30 & $<1$ & $<1$ & 5.00 & 3.20 & 3.04 & 4.38 & 3.10 & 3.23 \\
\hline 8 & 2.92 & $<1$ & $<1$ & 4.50 & 3.47 & 3.55 & 5.00 & 3.57 & 4.00 \\
\hline 17 & 3.94 & $<1$ & $<1$ & 4.96 & 3.15 & 3.21 & 5.81 & 3.60 & 3.62 \\
\hline
\end{tabular}

known (Jones and Greenfield 1982; Kuriyama and others 1993). Therefore, the dissimilarity between the kinetics of GR and LAB growth seems to make clear the important role of yeasts in the release of $\mathrm{CO}_{2}$.

Nonetheless, LAB also contributed significantly to gas release. This is clear when comparing the kinetics of LAB growth and GR for pizzas stored under $70 \% \mathrm{CO}_{2}$ with or without Nisaplin. Nisin inhibits the growth of LAB but has no effect on yeasts. The addition of
Nisaplin reduced $\mu^{\prime}$ (of LAB) notably, and this is presumably related to the lower $r^{\prime}$ for pizzas containing Nisaplin.

Nevertheless, the spoilage ability of LAB and yeasts does not only depend on the rate of growth, but also on the specific metabolic activity of the different species/groups growing on or in the product (Samelis and others 2000). Accordingly, to estimate the actual contribution of yeasts and $\mathrm{LAB}$, the activity of heterofermentative $\mathrm{LAB}$, homofermentative $\mathrm{LAB}$ and yeasts would have to be deter-

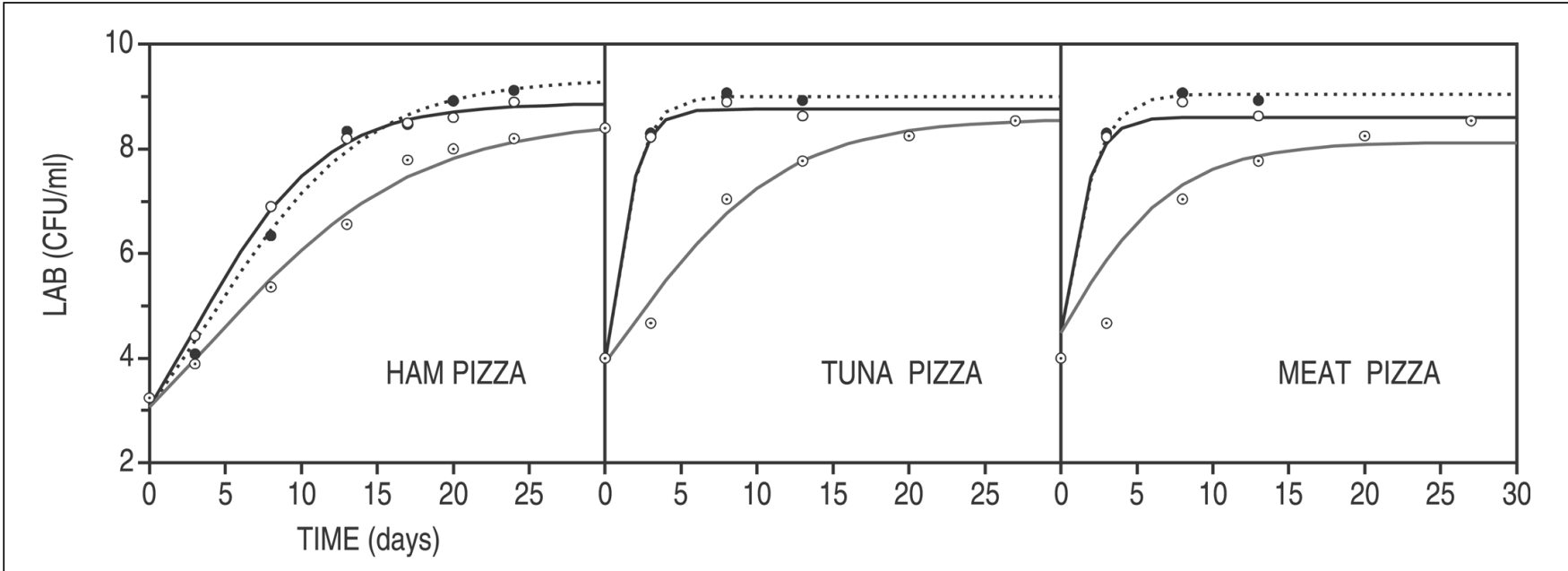

Figure 4-Growth of LAB in ham, tuna and meat pizzas stored under $20 \% \mathrm{CO}_{2}$ (broken line, 0 ), $70 \% \mathrm{CO}_{2}$ (unbroken black line, $\bigcirc$ ) and $70 \% \mathrm{CO}_{2}$ in the presence of $500 \mathrm{mg} / \mathrm{kg}$ of Nisaplin (grey line, $\odot$ ). Lines represent estimates from fits of Eq. 1 to experimental data (symbols).

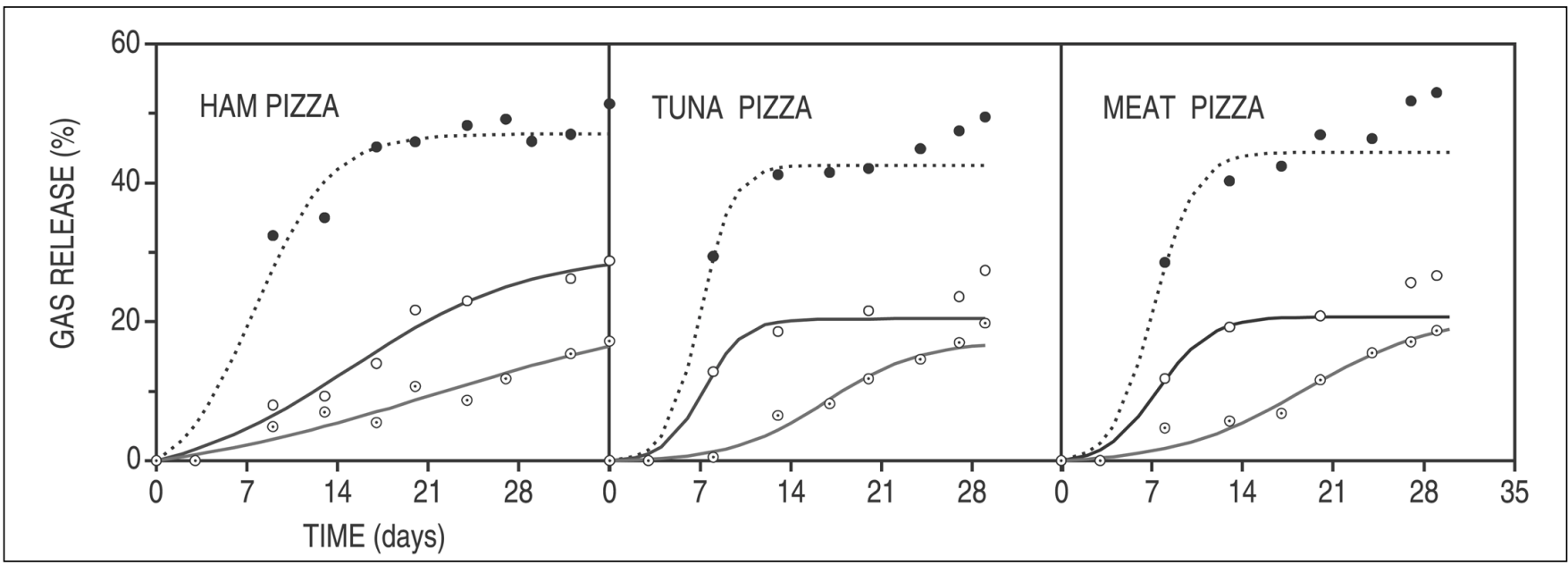

Figure 5-Gas release in ham, tuna, and meat pizzas stored under $20 \% \mathrm{CO}_{2}, 70 \% \mathrm{CO}_{2}$, and $70 \% \mathrm{CO}_{2}$ in the presence of $500 \mathrm{mg} / \mathrm{kg}$ of Nisaplin. Estimates and experimental data follow the notations of Figure 4 . Lines represent estimates from fits of Eq. 5 to experimental data (symbols). 
mined. Considering the highly complex microbial ecology of pizzas, monitoring GR is a clear advantage to assess the effects of $\mathrm{CO}_{2}$ and Nisaplin on the system.

Another feature of particular relevance shown in Figure 5 was that the amount of gas released started to increase markedly in some cases after 24 to $30 \mathrm{~d}$ of storage. The type of pizza, the presence or absence of Nisaplin and the proportion of $\mathrm{CO}_{2}$ in the gas mixture determined when this step started to occur. This result seems to indicate that some effect has been missed by Eq. 5, and therefore the model is only valid prior to that increase. Consequently, subsequent experimental data were excluded from fits of Eq. 5.

To verify whether or not GR actually stepped up markedly during the last days of storage, ham pizzas were processed as usual (see Materials and Methods) and packaged under $50 \% \mathrm{CO}_{2}$ and $10 \% \mathrm{O}_{2}$ in the presence of Nisaplin (500 mg/kg). Additionally, they were stored for $50 \mathrm{~d}$ so that the whole profile of GR was defined. It is to be expected that the addition of Nisaplin would inhibit the growth of LAB and as a result favor the activity of yeast due to a lesser degree of competition. The concentration of oxygen seemed to be critical (data not shown), since in pizzas containing a low initial proportion of oxygen (1\%) GR started to increase markedly once oxygen had decreased to very low values $(<0.5 \%)$ (Cabo and others 2001). It could be expected that a higher $\mathrm{O}_{2}$ concentration could show this point better and might help to clarify the role of LAB and yeast in gas release.

As clearly shown in Figure 6, GR followed a diauxic pattern. Both $\mathrm{LAB}$ and yeasts would have contributed to the release of $\mathrm{CO}_{2}$ during the first stage (see above). To account for the release of gas during the second stage, 2 alternatives can be considered:

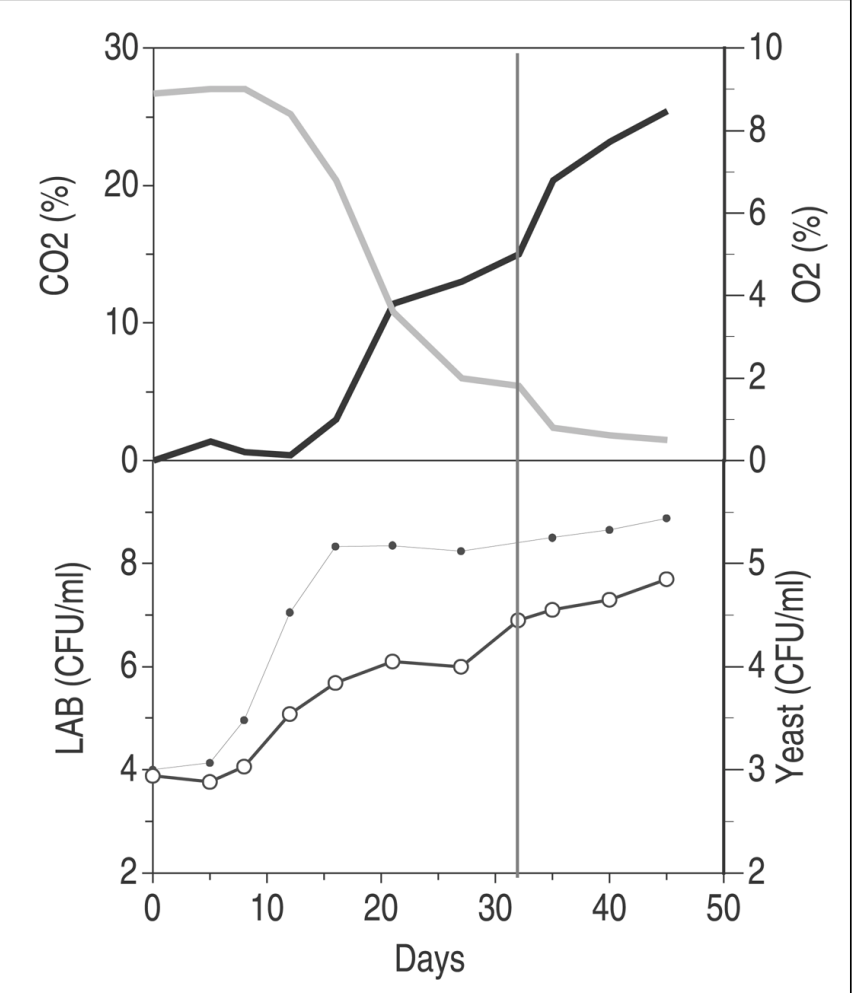

Figure 6-Patterns of $\mathrm{CO}_{2}$ released (black line, upper graph), $\mathrm{O}_{2}$ content (grey line, upper graph), LAB (O, lower graph) and yeasts $(\bigcirc$, lower graph) in ham pizza packaged under $50 \% \mathrm{CO}_{2}: 10 \% \mathrm{O}_{2}$ in the presence of $500 \mathrm{mg} / \mathrm{kg}$ of Nisaplin.
1. Gas release would have resulted mostly from an increased fermentative activity of yeasts.

2. LAB would still contribute too despite having reached the stationary phase due to a secondarization of the production of $\mathrm{CO}_{2}$ (Luedeking and Piret 1959).

However, some of the previous results would seem to support the former hypothesis. For instance, the release of gas during the second stage was less noticeable in ham pizza, which showed the lowest yeast counts (Table 3), than in tuna or meat pizzas. Or it was most marked when pizzas were subjected to the commercial treatment, that is, with the lowest $\mathrm{CO}_{2}$ concentration, since yeasts were least inhibited.

It is also clear from Figure 6 that the proportion of oxygen followed an inverse relationship with GR. The depletion of oxygen below a critical concentration might have triggered a shift in the metabolism of yeasts from respiratory to fermentative, and it would account for the high rates of gas release in the second stage.

Although it seems evident that GR followed a diauxic profile, storing pizzas for longer than 25 to $30 \mathrm{~d}$ does not seem appropriate in terms of shelf life. Consequently, the use of Eq. 5 appears to be adequate for practical purposes.

\section{Conclusions}

$\mathrm{M}$ OST MODELS HAVE BEEN AIMED AT DESCRIBING THE KINETICS OF growth of spoilage or pathogenic microorganisms in response to different factors (spoilage microflora: Mayer-Miebach and others 1997, Koutsoumanis and others 2000; Listeria: Castillejo and others 2000, Erkmen 2000). Modeling changes in chemical or sensory properties of complex food systems due to microbial activity is much less common. However, it may help to simplify the study of heterogenous food systems, and from an industrial viewpoint, even to control the critical points of production lines.

\section{References}

Ahvenainen R, Skyttä E, Kivikataja R-L. 1990. The influence of modified atmosphere packaging on the quality of selected ready-to-eat foods. Lebensm Wiss Technol 23:139-48.

Birzele B, Orth R, Kraemer J, Becker B. 1997. Influence of psychrotrophic yeasts on the spoilage of delicatessen salads. Fleischwirtschaft 77:331-3.

Borch E, Kant-Muermans ML, Blixt Y. 1996.Bacterial spoilage of meat and cured meat products. Intl J Food Microbiol 33:103-20.

Cabo ML, Murado MA, González MP, Pastoriza L. 1999. A method for bacteriocin quantification. J Appl Microbiol 87:907-14.

Cabo ML, Pastoriza L, Bernárdez M, Herrera JJR. 2001. Effectiveness of $\mathrm{CO}_{2}$ and nisin to increase shelf life of fresh pizza. Food Microbiol 18:489-98.

Castillejo-Rodriguez AM, Barco-Alcala E, Garcia-Gimeno RM, Zurera-Cosano G. 2000. Growth modeling of Listeria monocytogenes in packaged fresh green asparagus. Food Microbiol 17:421-7.

Church IJ, Parsons AL. 1995. Modified atmosphere packaging technology: A review. J Sci Food Agric 67:143-52.

Devlieghere F, Debevere J, Impe J van. 1998. Effect of dissolved carbon dioxide and temperature on the growth of Lactobacillus sake in modified atmospheres. Intl J Food Microbiol 41:231-8.

Erkmen O. 2000. Predictive modeling of Listeria monocytogenes inactivation under high pressure carbon dioxide. Lebensm Wiss Technol 33:514-9.

Jones PR, Greenfield PF. 1982. Effect of carbon dioxide on yeast growth and fermentation. Enzyme Microb Tech 4:210-23.

Koutsoumanis PK, Taoukis PS, Drosinos EH, Nychas G-J. 2000. Applicability of an Arrhenius Model for the combined effect of temperature and $\mathrm{CO}_{2}$ packaging on the spoilage microflora of fish. Appl Environ Microbiol 66:3528-34.

Kuriyama H, Mahakarnchanabul W, Matsui S, Kobayaski H. 1993. The effects of $\mathrm{pCO}_{2}$ on yeast growth and metabolism under continuous fermentation. Biotechnol Lett 15:189-94.

Lannguelongue M, Finne G, Hanna R, Nickelson R, Vanderzant C. 1982. Microbiological and chemical changes during storage of swordfish (Xiphias gladius) steaks in retail packages containing $\mathrm{CO}_{2}$-enriqued atmospheres. J Food Protect 45:1197-203.

Layrisse ME, Matches JR. 1984. Microbiological and chemical changes of spotted shrimp (Pandalus platyceros) stored under modified atmospheres. J Food Prot 47:453-7.

Luedeking R, Piret EL. 1959. A kinetic study of the lactic acid fermentation. Batch process at controlled pH. J Biochem MicrobTechnol Eng 1:393-412.

Lyhs U, Korkeala H, Vandamme P, Bjorkroth J. 2001. Lactobacillus alimentarius a specific spoilage organism in marinated herring. Intl J Food Microbiol 64:35560.

Mayer-Miebach E, Zanoni B, Speess WEL. 1997. A model to predict microbial 
contamination of blanched spinach. Lebensm Wiss Technol 30:536-42.

Murado MA, González MP, Vázquez JA. 2002. Dose-response relationships. An overview: A generative model and its application to the verification of descriptive models. Enzyme Microb Tech 31:439-55.

Samelis J, Kakouri A, Rementzis J. 2000. Selective effect of the product type and packaging conditions on the species of lactic acid bacteria dominating the spoilage microbial association of cooked meats at $4{ }^{\circ} \mathrm{C}$. Food Microbiol 17:32940 .

Sameshima T, Takeshita K, Akimoto M, Yamanaka H, Miki T, Arihara K, Itoh M, Kondoh Y. 1997. Effect of various sugars on the swelling spoilage of cooked meat products caused by heterofermentative lactic acid bacteria. J Jpn Soc Food Sci Technol 44:855-61
Westall S, Filtenborg O. 1998. Yeast occurrence in Danih feta cheese. Food Microbiol 15:215-22.

MS 20020424 Submitted 7/16/02, Revised 9/12/02, Accepted 10/1/02, Received $10 / 10 / 02$

The authors thanks Luisa Iglesias, Lorena Barros, Irene Tarrío and Carlos Suárez for their technical assistance. This work was supported by CICYT (Inter-ministerial Committee of Science and Technology, PETRI project 95-0324-OP).

Authors Cabo, Pastoriza, and Rodrguez are with the Inst. de Investigacións Mariñas. C/ Eduardo Cabello, 6. 36208 Vigo (Pontevedra). Direct inquiries to author Cabo (E-mail: marta@iim.csic.es). 